\title{
Reciprocal Learning Between Canadian and Chinese Schools Through the 24 Nature Notes Project
}

George Zhou

University of Windsor

Sonia Wai-Ying Ho

University of Windsor

Yuanrong Li

Southwest University

Mingyue Luo

Southwest University

Haley Freedman

Prince Edward Public School

Jian Luo

Southwest University Affiliated Middle School

\begin{abstract}
The 24 Nature Notes project was part of the China-Canada Reciprocal Learning Program. Two sister schools participated in the project. Following the same set of dates, students from both schools conducted outdoor observations and collected data. Skype meetings were arranged to exchange ideas and share student work. This study aims to understand the impact of the project on Canadian and Chinese teachers and students, what they learned from each other, and what challenges they faced. Data was collected through observation notes, meeting minutes, student work, and interviews with both Chinese and Canadian teachers and students. Data analysis revealed that the project was a positive opportunity for participants from both countries to gain cross-cultural understanding. The Canadian students enjoyed the freedom in topic selection and presentation formats. They particularly liked the life lessons that the Chinese students shared through their work. The Canadian teachers also valued the idea as it allows students to reflect their observations from a different context. The
\end{abstract}


Chinese teachers and students appreciated the Canadian students' creativity. They gained inspiration from Canadian teachers and students and as a return their project work became more creative.

\section{Introduction}

In the contemporary globalized world, education is under increasing pressure to equip students with skills for their future success. In order to meet the needs of international currency, schools form, on a daily basis, a knowledge "delivery model" (Broadfoot, 2000). Governments face a similar situation to seek for changes in education with a pressure on student performance. Supranational organizations, such as the Organisation for Economic Co-operation and Development (OECD) and the International Association for the Evaluation of Educational Achievement (IEA), promote international tests (e.g. the Programme for International Student Assessment [PISA] and the Trends in International Mathematics and Science Study [TIMSS]) to measure students' academic performance. The tests place an emphasis on quantifiable measurements, and comparative research has been conducted to "find out what work and to use such insights to inform educational policy-making and educational practice" (Broadfoot 2000, p. 366). Other studies that involve the measurement of students' achievement have been conducted to generate a better understanding towards the curriculum (IEA, 2018). Data collected from these studies is used to compare student's educational performance internationally, and factors which affected students are interpreted in order to foster academic achievement (Beaton et al., 1996; Carnoy, Khavenson, Loyalka, Schmidt, \& Zakharov, 2016).

On the other hand, studies have also been conducted to investigate students' collaborative experiences with international partners. The findings from these studies revealed that students from different countries obtained successful educational experiences (Ligorio \& Van der Meijden, 2007; Wang, 2012; Yang, Yu, Chen \& Huang, 2014). However, there has been relatively little research on how international collaborative education is being implemented in Canada, particularly at the elementary school level. The 24 Nature Notes project helped to fill this gap by focusing on students' learning experiences. The project was a part of the Canada-China Reciprocal Learning in Teacher Education and School Education Partnership Grant Project funded by Social Sciences and Humanities Research Council (SSHRC). Teachers from two sister schools integrated the 24 Nature Notes project into their curriculum. The students conducted nature observations in their local communities, and based on these observations, the students completed various projects stepby-step individually or in groups. Video conferencing through Skype regularly took place between the schools for participating teachers and students to exchange ideas and share work. This study was not designed to compare students' educational attainment, but to explore the impact that the program had on teachers and students who participated in this unique international collaborative journey. This paper, therefore, intends to answer the following research question: What impact does the 24 Nature Notes project have on teachers and students in the Chinese-Canadian sister schools, and what did they learn from each other? 


\section{Literature Review}

The 24 Nature Notes project was designed using the framework of reciprocal learning, which is increasingly taking hold in comparative and international education. Traditionally, comparative and international research mainly focused on investigating the differences between the education systems of two or more countries and to advocate for how and what one country learns from another. It has been more or less a static approach that mainly focuses on one-way knowledge transfer (Cowen, 2006). With the fast pace of globalization, contact and collaboration between countries have increased dramatically in all areas of society, including in educational settings. This increase creates a new opportunity for comparative and international education to move from static approaches to dynamic approaches which address mutual learning experiences in the context of reciprocal interactions (Lewis, Sellar, \& Lingard, 2016). Researchers can explore differences, contradictions, negotiations, real life changes, mutual learning, and benefits in the process of interactions between participating education organizations, educators, and learners (Carney, 2009). Reciprocity of learning is the key idea built into such new perceptions of comparative and international education. Under this new perspective, cross-cultural learning needs to go beyond simple comparison in practices, values, and results and move to a paradigm that emphasizes twoway learning processes in the context of acting together (Connelly \& Xu, 2015). As emphasized by Boud (1999), the two-way, reciprocal learning experiences should involve:

Participants learning from and with each other in both formal and informal ways. It includes mutual benefits and a sharing of knowledge, ideas and experience among participants. The emphasis is on learning rather than teaching, and on the support and encouragement learners offer to each other, as much as the learning task. (p. 6)

The 24 Nature Notes project was designed as a school-based and science-related collaborative program. It also included a research plan that studied the participating teachers' and students' respective experiences in the cross-cultural learning process. Chang Rundgren (2015) suggests that a comparative study of cross-cultural learning should be embedded in educational practices, with an aim to facilitate the development of new pedagogical actions. He highlights the important roles of teachers in such efforts and suggests researchers should collaborate with teachers in a way that will enable them to develop their professional knowledge and teaching practices. In regards to the cultural influences, Chang Rundgren recommends that when researchers and teachers are evaluating ideas developed in another culture or country, they should be aware of reflecting on the good and important aspects of the local culture.

The 24 Nature Notes project involves a combination of activities that take place inside and outside of the classroom, and blends informal (outdoor observations) and formal learning experiences (in-class research). Some studies have reported on the impact on students' learning experiences as a result of outdoor educational activities (Hofstein \& Rosenfeld, 1996; Robertson, 2007). Hofstein and Rosenfeld (1996) indicated that the out-of-school project is an informal mode in science learning and fosters students' learning, helping them to become "independent and 
autonomous" learners. Robertson (2007) reported that through an out-of-school activity, such as an environmental field trip, the quality of science education is enhanced. Students received cognitive, affective, and social benefits from this informal learning experience.

The 24 Nature Notes project was an adapted format of project-based learning. Projectbased learning engages students in learning authentic knowledge through project work (Tan \& Chapman, 2016). It is seen as more effective than traditional teaching methods, as the project work is a learning experience where students deal with real-world challenges (Thomas, 2000). Bell (2010) reported that students effectively obtain information through the process of doing a project. This approach encourages students to conduct their own project and take on the role of an initiator of their own learning. In return, students can become self-responsible, independent, and disciplinary learners. Project-based learning shifts away from the traditional way of teacher-led or teacher-centered teaching to a more student-directed learning process. Teachers switch their role to that of a provider to equip students with necessary knowledge that is required for doing their projects (Tan \& Chapman, 2016).

As Tan and Chapman (2016) observed, project-based learning is implemented well in both North America and Asia. In the United States, project-based education is successfully delivered at the elementary, secondary, and postsecondary levels, even through graduate level programs. In Asian schools, project-based learning is receiving increasing attention and group projects are being implemented in schools at different levels within each country. However, Tan and Chapman's (2016) study reports that project-based learning in the context of international collaborations is rare. Among the few exceptions, Yang, Yu, Chen, and Huang (2014) studied a cross-cultural online collaboration learning program between Chinese and U.S. schools. They found that culture had an influence on learning strategies. Their findings also revealed that students from both sides demonstrated positive attitudes, and they were interested in each other's culture (Yang et al., 2014). In international collaborative project-based learning, information technology plays an essential role to engage students in interactions and discussions in a virtual space. Participants can interact with their partners from a different country synchronously or asynchronously through technology (Ligorio \& Van der Meijden, 2007; Underwood, Smith, Luckin \& Fitzpatrick, 2007; Wang, 2012). Wang (2012) explicitly indicated that a practical online platform such as Facebook can host a successful cross-cultural collaboration, but teachers need to consider students' learning motivation and pedagogical design. Ligorio and Van der Meijden (2007) conducted a multinational project to investigate the successful partnerships which took place in seven middle schools located in Italy and the Netherlands. The participating students were 9 to 14 years old. Two online platforms were developed to engage students: a forum for discussion and a three-dimensional virtual world for storing notes and documents. The researchers attributed the success of the project to several factors including the availability of computer equipment, the quality of interaction with partners from another country, a sense of belonging developed from an in-class community to a virtual community, and competent teachers who can provide adequate instructional strategies (Ligorio \& Van der Meijden, 2007). 


\section{Context of the Study}

Based on the expectation of developing reciprocal learning relationships, two Canadian and Chinese schools agreed to participate in the 24 Nature Notes project in 2015. This partnership program has run for three school years, from September 2015 to May 2018. Teachers from both sides chose a solar term to conduct the project according to their class schedules. The choices of observation time refer to the Chinese nature notes, which specify the 24 points where the weather noticeably changes around the year. Students were taken outside to observe nature, and as a result of their observations they chose a topic of interest to work on. The choice of topics was driven by students' personal interests. Teachers from both countries designed the project according to their curriculum and school contexts.

In the first year, two video conferences were held, and two exploratory activities were shared between two participating schools. From September 2016 to May 2018, the learning space was successfully built and regular communication pathways were set up for both sides. Five collaborative activities took place, and six video conferences were organized for students to exchange their research progress and/or share their final work. The teachers also took these chances to build rapport, further enhance their understanding of each other's culture, and exchange thoughts and ideas for the purpose of making the project a better learning experience.

The two sister schools that were involved in the project are quite representative of the cities of Windsor, Ontario, Canada and Chongqing, China. On the Chinese side, the participating school is affiliated to the Southwest University (SWU). According to the Chinese school's website (Southwest University Affiliated High School, 2014), this is a school directly under the jurisdiction of the Ministry of Education of the People's Republic of China and is also a key school in the Chongqing City Department of Education. The school has an excellent academic reputation in Chongqing, and the students in this school have high academic standing. Like the other Chinese secondary schools, science subjects are taught as separate classes, including biology, chemistry, and physics, for example. This school has several different science teachers to teach different subjects due to its large student population, and it traditionally provides an enriched environment for science education. The 24 Nature Notes project was first launched in this school in 2013. It was further developed into a scientific activity due to the fact that the designer of the 24 Nature Notes project was the lead science teacher at the school, and those who implemented the project were also from the science team. They became strong supporters in conducting this project, hence, it is no surprise that this project has continued to run smoothly from a scientific perspective. The school teaches students from grades 7 through 12, though this project was implemented at two levels: grades 7 to 8 and grades 9 to 11. The project became a part of the science curriculum and was implemented in different dimensions. Students can take on the 24 Nature Notes project as their science class requirement or as an extra-curricular activity. The choice of participating in the project was fully based on students' personal interests. The project required frequent nature observation, so parental involvement became a support. Parents normally took a role as a material supplier or transportation provider. 
On the Canadian side, the public elementary school involved in the project is located in a low socioeconomic community where students have diverse ethnic backgrounds. The school runs from Kindergarten to Grade 8. Like other Ontario schools, each class has a homeroom teacher who is responsible to teach a majority of school subjects. The teachers who were responsible for the design and implementation of the 24 Nature Notes project were not responsible for teaching science. This created some obstacles when the school started to run the project in the 2015-16 school year. The teachers spent a year exploring some of the possible ways to integrate the project into their curriculum, but it did not go very well. However, both sides built a mechanism of information exchange during this year. Back-and-forth discussions were held in order to clarify the primary focus of the project. Two video conferences were conducted and students shared information that they observed about nature as well as the work that they had done to represent their learning. A breakthrough came in September 2016 when two teachers took over the project and successfully integrated the project into the language arts curriculum in grades 7 and 8 . In order to reflect the project's scientific nature to the greatest extent possible, the teachers made the project into an inquiry-based learning activity. A work package was designed by one of the teachers for students to develop knowledge, design their presentation of such knowledge, and record information that they found. The goal that the teachers set for this project was to enable students to learn the combined knowledge of language arts and science. The students who participated in the 24 Nature Notes project were mainly from two Grade 8 classes and one Grade 7/8 split class. Some of them were identified as English as a second language (ESL) students. The students' project work involved outdoor observation, information searching, group discussions, filling out work packages, and designing ways to demonstrate their learning. Most of the work related to the project was completed in school, but sometimes students were required to use their weekends and holidays to work on the project in order to meet the set timeline. Therefore, parental involvement was not expected.

\section{Methodology}

This project was participatory qualitative research. The researchers were among the key members to coordinate the project and facilitate communications. Data collection started in 2015 on the first day of the project implementation; the majority of data was collected during the 2016-17 and 201718 school years, as the research team conducted regular school visits and facilitated the research process for these two years. The research team accumulated rich data which can be summarized in three types: a) documentary data, b) observation notes, and c) interview data. These multiple types of data helped the researchers to assure the validity of this study and enhance the transferability of findings (Burns, 1994) as these documentary and observation data allowed for triangulation with interview data (Punch, 2005).

\section{Documentary Data}

Documentary data were collected during class visits and project meetings over a period of three years. They included project meeting minutes, video conference minutes, and photos that 
captured students' work processes and final work products. The minutes included teachers' thoughts and ideas that they exchanged with their partner school, and information about students' performance and experience while sharing work in presentations through video conferences. Photos of the students' products were collected as valuable data as they led to the identification of changes in students' work. The changes included their perception of the project, which affected the topics that they chose and the ways that they used to present their work.

\section{Observation Notes}

Observations were made at different stages of the project and information was recorded about various components of collaborative student work, including nature observation, inquiry question generation, discussions with partners, topic selection, and presentation design. Student observation reports consisted of the information that they searched for, the data that they collected, and the ideas that were generated for their Nature Notes projects. Class observation notes documented the teachers' instructional methods, their mutual understandings and interpretations of the project and each other's cultures, and how such interpretations and understandings reflect on the project's implementation.

\section{Interview Data}

In order to collect participating teachers and students experiences and perceptions of the project, interviews and focus groups were conducted at the end of the second year and the middle of the third year of the project's implementation. Two Canadian teachers (both females) participated in one-on-one semi-structured interviews. Eleven Canadian students participated in two face-to-face focus groups. One focus group took place with six Grade 8 students, three females and three males. The other group had five student participants, all females. Two Chinese science teachers (both male) and three Grade 10 and three Grade 8 Chinese students (2 males and 4 females) were interviewed individually through teleconferencing. These interviews and focus groups captured students' and teachers' perceptions and experiences toward various aspects of the project. Teachers recalled their experiences of preparing and conducting the project, students' performances, the changes of their views towards each other's culture, the learning from sister school teachers, and their perception about such international collaboration. Students shared their experiences and feelings about how they explored their topics, how the project contributed to their science learning, what they learned from their sister school counterparts, and their suggestions for improvement of such international collaboration. In sum, the data gathered from school visits, video conferences, and interviews provided researchers sound information to generate understanding of how teachers and students from the two sister schools experienced the project and impacted each other through the project.

\section{Data Analysis}

An inductive approach (Berg, 2009; Miles \& Huberman, 2014) was adopted for data analysis. It includes three concurrent flows of action: data reduction, data display, and drawing and verifying conclusions. The researchers first read through all text information several times, 
word by word, to label all key points and topics and capture any possible deeper meaning from participants' narratives, researchers' field notes, meeting minutes, and photos. Cross-reading of all types of data was conducted for an accurate understanding of participants' learning experience and achievements. The initial coding and memos were modified, classified, and assembled according to several themes. Data analysis was cross-checked by the research team to assure the inter-rater reliability.

\section{Study Results}

\section{Positive Experiences}

Both the participating teachers and students from the two sister schools highly valued the project as a positive learning experience. For the Chinese teachers, the positive impact they gained was to have "actual practice" in the science field. Teacher $L$ reported that the project allowed him to "pay attention to the nature and to the creatures" that they had seldom noticed before. Teacher $X$ indicated that this project was designed as "a cover for the shortage in traditional education." After doing the project, a positive impact on the Chinese students was that they gained a general understanding of the real world by using an integration of multidisciplinary knowledge. The students also learned to record observations. Teacher X explained that the project "fostered students to observe even more carefully." Teacher L felt that students who participated in the project showed higher interests towards science than those who did not get involved. In short, students' self-motivation towards science learning increased.

Beyond these academic impacts, the project had a profound influence on other aspects of student life. Teacher $\mathrm{X}$ shared one student's amazing experience when she and her dad were going to the wild for observation:

A student usually had little interaction with her dad who was a businessman. Once, her father took her to observe nature and shared some childhood stories with her. She found that her dad was a very interesting guy. This made her feel that her relationship with her father had changed, and since then, they had more interactions. (Teacher X, personal communication)

The teacher commented that this project really helped foster parent-child communication and improve their relationship. He felt touched as "this important achievement is beyond the educational goal that was originally set for the project."

The Canadian teachers enjoyed participating in this project because-influenced by their Chinese partners - they learned to view nature from a new angle. Teacher F liked the whole idea behind the 24 Nature Notes project being supported by the Chinese culture. She enjoyed communicating with the Chinese side. Teacher $F$ felt that it was very interesting to experience the same thing as the Chinese teachers did, but in completely different ways. She gave a detailed explanation to this thought: 
This project really forced me to look at things in different ways that I haven't done in the past...Every time that we would share with our Skype meetings and I would learn something new...I was able to have discussions afterwards about the things that we have learned... I think that kind of self-reflection aspect is very valuable as a teacher. (Teacher $\mathrm{F}$, personal communication)

Teacher F liked this project because she expanded her own knowledge through her participation.

To Teacher $H$, this was a project that she "would not have thought about doing" in her class, and she "was excited to try something new." She viewed the project as a great learning experience, not only for herself but also for her students. She reported that the experience of participating in this project was beyond her expectations.

During the focus group interviews, the students shared their personal feelings respectively. Canadian participating students felt that the 24 Nature Notes project was an interesting experience for them. The reasons that they felt this way can be summarized in the following four ways: a) the possibility of experiencing nature and connecting with animals and plants, b) the freedom of choosing topics and presentation forms, c) the chance to learn new things about nature, and d) their expanded understanding throughout the project.

On the Chinese side, all participating students reported positive experiences with the project. Students were dedicated to their task and learned more than they would have during classroom lectures. Student $Q$ was encouraged by her science teacher to participate in the Nature Notes project. She spent 25 days studying a caterpillar. She brought the caterpillar everywhere she went so that she would never miss observing any minor changes. She took pictures of it every day to document her daily observations. Student $E$ indicated that the project was meaningful as the outdoor observation set her free and helped her "balance the heavy workload" of her study. She enjoyed doing the project because she could "learn and extract knowledge beyond the textbook."

\section{The Effectiveness of the Project Implementation}

On the Chinese side, the project has been ongoing for two years before it was officially introduced to the Canadian sister school. According to Teacher L, the project was first launched in their school and later became a popular program in the local city. It was designed to be implemented in two dimensions: either as an integral component of the mandatory science curriculum or as a specific topic for elective courses. Students who participated in the project either conducted their study during school hours or in their spare time. The actions that the Chinese teachers took, as summarized in their sharing during video conferences and interviews, included teaching knowledge related to the 24 Nature Notes, taking students to observations, encouraging students to pick an interesting topic, and facilitating students to study their chosen topics. The school held competitions as a way to increase students' interest and engage them to continue participating in this project. Participating in the project was rewarding. Teacher L explained that, "we reward them if students show excellent work in this project. We will continually nurture them when they enter our high school. The project also helped some students to get admission offers from good universities." Such rewards are especially convincing to the senior students as the 
project opens up a better future for their education. In general, Chinese teachers made every possible step to make the project a successful experience for their students. Through participating in the multiple activities which were specially designed for the 24 Nature Notes project, students became confident learners as they received recognition from the school and teachers. Their satisfaction and achievements reflected that the project was successfully implemented.

In the Canadian sister school, the teachers integrated the 24 Nature Notes project into their literacy curriculum, and made it into an inquiry-based learning project. In other words, they combined both teaching goals into one single project, and students had to fulfill successful criteria that covered aspects from both curriculums. Students were allowed to work in groups or individually. In order to increase the effectiveness of the project, participating teachers designed a work package to help students to sort out their thoughts and ideas and prioritize their tasks. Practice sheets were provided as a guide for the students. Students could take the package home during breaks. Professional instructions were provided by the teachers according to students' interests and their research plans. The inquiry-based package included the following contents: a) selecting a topic and planning an inquiry, b) retrieving information, c) evaluating sources, d) processing (include learning to complete an MLA-style bibliography), and e) an assessment rubric for selfreflection. Students were expected to complete five steps for their inquiry-based project. Teachers chose a start date based on the 24 solar terms and according to their class schedules. They started the project by taking students to the school yard for observations. Students equipped themselves with the necessary tools - such as gloves and containers - to collect materials for future use. They also took this opportunity to experience nature and to document necessary information. They then filled out weather details on the nature notes observation sheet: temperature, humidity, heat index, sunshine duration, and air quality. Next, after sorting out the materials that they collected, the students chose a topic based on their personal interests. In the third step, each student chose a broad area of inquiry and created an inquiry question that they were expected to research (filling out the project planner). In the fourth step, students chose a method that they were going to use to demonstrate their learning and filled out the nature notes contract. In step five, students chose to answer one of the two questions posed by the teacher as a final reflection.

This inquiry package was designed in a well-organised format. It was a systematic way to help students complete their project. It is worth noting that there was a contract for students to sign. The purpose of this action was to help students assure their commitment to complete the project by a deadline. What impressed the students most was that they had the freedom to choose their topic and demonstrate their work in whatever way they wanted to. Besides that, students' willingness to participate in the video conference sharing was also respected by their teachers. In other words, the project was mostly driven by the students' personal interests, and they enjoyed this flexibility. The students were extremely satisfied because they had never experienced such full freedom in other assignments. This feeling was essential to students and consequently kept them highly motivated to participate in and complete the project in a timely manner. The creativity of their products, the confident attitudes that were shown in the video conferences, and the satisfaction that was demonstrated in the interviews together lead to a conclusion that the 24 Nature Notes project was successfully implemented by the teachers in the Canadian school. 


\section{Respecting and Learning from Each Other's Culture}

A meeting was set in November 2016 between the research team and two Canadian teachers who were willing to participate in the project. They received background information about the project. While they individually learned the background knowledge, they consulted the research team whenever they had questions in regards to their plans for implementation of the project in their classes. The teacher participants appreciated the chance to learn about Chinese culture, such as the 24 solar terms and the twelve constellations. Teacher F reflected:

I felt that I wasn't aware of how the season changes while observing China before this. I have no idea about the whole aspect here, like the solar terms and the 12 constellations...It is completely different from everything I have ever learned, but that's what I enjoyed. (Teacher F, personal communication)

Teacher F believed that "self-reflection is very valuable as a teacher." She realized that a lot of things made sense after reading materials that were provided to her by the research team. "Like the Awakening of Insects...that make [sic] sense... from a cross-cultural point of view. It is very interesting for myself." She enjoyed learning about "how different cultures experience the same things but in completely different ways" because that increased her knowledge.

From the point when Teacher F took over the project, she attended every video conference and was prepared to learn new knowledge. A Chinese student shared a story about a pair of parrots that she observed in one of the video conferences. In her sharing, one parrot escaped from the cage but it did not fly away. It seemed that it was unwilling to leave and waited for its partner. It flew away with its partner once the student let go of the other parrot inside the cage. The Chinese student interpreted this as a romantic story - the two parrots stay loyal to each other. She then connected such observation with human family life and moved on to criticize the ever-increasing divorce rate in China. Another Chinese student shared her observation of a tree in his grandmother's backyard. The tree top was broken off by a storm one year. She felt sad about the tree and believed it would not survive. However, the tree grew new leaves the next spring. She commented that a person's life could be like this. Everyone might have times of difficulty, but he or she should not give up and always stay optimistic for future opportunities. Teacher F was enlightened by the idea that the Chinese student learned such life lessons from her nature observations. Teacher $\mathrm{F}$ shared her excitement in that meeting: "what a fantastic idea it was." She delivered her appreciation to the Chinese teachers and students. She also took notes about the idea and decided to incorporate this life lesson idea into her next round of the project. As a result, Teacher F revised the student inquiry work package by adding the following two questions for the next chosen solar term, Awakening of Insect:

1. What lesson did you learn about life through understanding your chosen insect or animal?

2. What do you see differently now that you know about your insect or animal? 
Through this exchange of ideas, Teacher F acknowledged the cultural differences between the two countries. She not only valued the differences, but was also willing to open herself up to accept new ideas. The other Canadian teacher, Teacher $\mathrm{H}$, said that she also liked the idea of gaining personal reflection from the project. Teacher H particularly liked the life lesson idea because "kids like story and it increases their level of engagement." She "was so excited" to learn about this idea, although she did not build that into her next design of the program. In her future teaching, she promised to "take more opportunities to build that in."

When speaking of the Canadian students' attitudes towards cultural differences, according to the two teachers, their students also loved the idea of the life lesson. In Teacher H's Grade 8 class, she had a discussion with students after the video conference. One of her students told her that the Chinese students "included a moral lesson, like the legend building" in the project. The students hoped Teacher $\mathrm{H}$ would incorporate that idea in their project. In Teacher F's class, the two new questions made her students look at animals, plants and nature from a new perspective. Her students welcomed this addition. In the group interview, all Grade 8 students reported that they liked the idea of writing stories to reflect on what they learned from nature. Student $D$ shared her view by giving an example. She stated that Chinese students "always have really interesting stories. Like that girl who talked about the tree. That was like a real story, and it was cool." Student $A$ elaborated on her feelings: "it is easier for you to relate to the animals when you learn the similarity between you and the animals."

To form a life lesson like their Chinese counterparts did was a new experience for the Canadian students. They appreciated the Chinse students' inspiration in creating stories related to human life. They were willing to try the Chinese way. Student $J$ studied caterpillars and observed their transformation from ugly and imitating forms to beautiful butterflies. She shared a life lesson she learned from her observations: "people should not judge other people based on their appearance." This example showed how a student's understanding can be advanced beyond just simply doing a regular project to forming a deeper understanding of life. This change suggested that the influence of the Chinese school impacted Canadian teachers' implementation of the project and students' views on human relationships.

Despite the nature observation, the Canadian students also noticed some differences between themselves and the Chinese students in terms of the ways they completed the project. They appreciated the Chinese students' artistic talents as they always drew beautiful pictures. However, Student D proposed a critical point: "they all presented their work in the same way. They all drew pictures." Unlike the Chinese students, Canadian students presented their work in multiple formats. The Canadian students appreciated their freedom and were proud of their own creativity because it "makes the project more fun". Noticing these differences, the Canadian students gave some suggestions to their Chinese partners. They suggested the Chinese students can "change the way of presentation instead of just doing it like a picture and writing," so that the Canadian students can see the Chinese students' unique ways of presentation.

On the Chinese side, participating students appreciated the Canadian students' innovative ways of presenting their learning and capabilities in searching for information. Chinese Student $L$ recalled that "a Canadian student shared that he would present his project as a song. The influence 
to me was that: you observe the creatures with your eyes, but you can use a variety of ways to present what you learned." Chinese Student $P$ shared her thoughts: "they found a lot of professional thesis...I will learn from them to search for professional articles and learn to read thesis [sic]." However, Chinese Student $Q$ had an opposite opinion on this matter. She was not impressed with the presentation methods that many Canadian students preferred. She suggested that "instead of just simply searching for information from the internet, they should obtain data by doing more experiments." While at the same time, Student Q pointed out an excellent Canadian style: the handmade products. She also brought up that "the Canadian students showed a higher interest to [sic] nature than the Chinese students... They were also happy to exchange ideas with us even though they had to go to school earlier for video conferences."

The Chinese teachers also highly valued the Canadian students' creativity in the work that they demonstrated. In one of the video conferences, a Canadian student presented a threedimensional butterfly model; this piece of art surprised all Chinese video conference attendees. The Chinese teachers appreciated the innovations showed in the Canadian students' work. They were inspired by the Canadian children and decided to add new requirements in the next round of the 24 Nature Notes project. The Chinese teachers encouraged their students to learn from the Canadian partners and explore new ways to present their work. According to the lead science teacher, Teacher L, this encouragement worked very well, as they saw significant changes in their students' work. As a result, Chinese teachers collected many more three-dimensional projects than in the previous round of the project.

\section{Limitations}

For Canadian teachers and students, the primary problem that they faced was time. The 24 Nature Notes project was not a part of the Ontario Grade 7 or Grade 8 curriculum, and teachers reported that they had to find additional time to conduct this project. Teacher $\mathrm{H}$ said that "my only challenge was making sure that we have enough time." Since their schedule was tight and each project consisted of several steps under the inquiry-based design, the teachers found it hard to rush several projects in one school year. They suggested to slow down the pace so that students have time to do a better job. Consequently, only two projects were completed in the third year.

Another limitation that the Canadian students faced was a lower frequency of nature observations due to weather conditions. Student A indicated that "the season changes a lot in China, they have more seasons than us...they have a lot more species than we have here." Windsor is a lot colder than Chongqing, and winter in Windsor can last nearly six months, so students were unable to find as many animals or plants they liked to observe during the school year. At occasions set by the 24 Nature Notes, the Canadian students tried but were unable to find insects or animals in the school yard. They therefore had to rely on second-hand resources to finish their projects.

The other limitation for the Canadian students was a lack of chance to observe nature after school due to their parents' unavailability. According to Teacher F, "it would be very challenging" to get parents involved in their children's school activities. The school is located in a low socioeconomic area of Windsor. Many parents need to work and may not be able to spend much 
time to take their children to natural environments. This limitation also forced some students to search for information from the internet instead of collecting data from nature.

The Chinese students conducted multiple nature observations and accumulated much different data. They felt it hard to demonstrate all their learning in the limited space on one page of A4 paper as the school required them to do. Their challenge was to select the most representative data to show their learning. Besides this, Student $\mathrm{P}$ and Student $\mathrm{Q}$ both believed that choosing an appropriate way to demonstrate their work would be another difficulty.

According to the Chinese lead science teacher, Teacher L, he found that the time zone differences and internet problems created obstacles for video conferencing. The internet problems affected the quality of communication and the time difference influenced the coordination of meetings and the length of communication. Hence, teachers and students were not able to always have smooth interactions online. These were the major challenges that both sides faced.

\section{Discussion and Conclusion}

The 24 Nature Notes project was part of the reciprocal learning program between participating Canadian and Chinese schools. It adopted the perspective of reciprocal learning as a collaborative partnership (Xu \& Connelly, 2017). The project was designed as a practice-based, international collaborative activity with a focus on cross-cultural experiences. It aimed to foster an exchange of ideas and share teaching and learning experiences between participating schools located in two different cultural and educational contexts. Data showed that the project was a rewarding experience for participating teachers and students from both countries, although there was space for improvement of the quality of collaboration. Participating teachers and students enjoyed the cross-cultural experiences. They developed a broader knowledge and a deeper understanding of each other's culture as Gillespie and Melber (2014) suggest should be a result, from their study of an international collaborative program with a focus on science learning. The understanding of each other's differences equipped participating teachers and students with an open-minded attitude so that they could not only sense each other's strengths but also understand each other's limitations. Such open-mindedness is necessary for any participants to have in a reciprocal learning program.

\section{Positive Experiences}

In this project, the students from both sides were given freedom of choice in selecting a topic that interested them. Students highly valued and enjoyed this freedom of learning as it helped them became self-motivated learners. Through the project, participating students demonstrated strong self-awareness and high curiosity. The Canadian students highly appreciated the freedom of choosing topics as well as choosing presentation methods. They realized the differences between themselves and the Chinese students and were willing to learn from their Chinese counterparts. They were confident about their own creativity as many of them have the talents to demonstrate their learning in innovative ways. Meanwhile, they were inspired by Chinese students to reflect on life lessons learned from nature observations. 
Similar to their Canadian partners, the Chinese students also highly valued the experiences of working on the project. Their interests in nature increased as they verified knowledge that they had learned through observations in the wild. The positive impacts that the project brought to them included: a) setting them free from a heavy school workload, b) opening their eyes to view nature from a new perspective, c) respecting their personal interests, and d) giving them the freedom to learn. They were delighted with these learning opportunities as they had never experienced them before. They were proud of their projects and learned new ways of presenting their learning from interacting with the Canadian students.

Teachers from both sides viewed the differences between the two cultures positively. Like their students, they respected the differences and learned from each other's strengths. The Canadian teachers were open-minded and they implemented the curriculum with a flexible approach. The teachers were the project designers, but they were also willing to listen to the students' opinions, having discussions with the students about the additional requirements for the project. This student-centered school culture gave students the freedom to explore their interests. Students were allowed to choose their favourite topics as well as choose the interesting ways to present their findings. The Chinese teachers noticed the Canadian teachers' strengths when both sides exchanged thoughts and ideas. Due to such appreciation, the Chinese teachers were willing to adjust and give their students more freedom.

\section{Cross-Cultural Influences}

The Canadian teachers and students learned about Chinese culture from the project. The 24 Nature Notes are categorized as indigenous knowledge that reflects how the Chinese developed their unique time system. There are 24 specific points during the year when the weather noticeably changes. This system reflects how ancient Chinese viewed seasons, weather and the human-nature relationship. The Canadian teachers learned this Chinese tradition and culture from their counterparts as well as from the research team. They then delivered this knowledge to their students. In addition, the Canadian teachers were eager to try out new ideas while being culturally sensitive to the Chinese style of thinking. Their willingness to self-adjust showed that the Canadian teachers were open-minded to Chinese ways of teaching and learning. The Canadian students followed the lead of their teachers, and were open-minded and willing to try new things. They discovered the strengths of their Chinese partners and appreciated the efforts that they made. These characteristics motivated the Canadian students to achieve success in their project work.

The Chinese teachers and students noticed that the Canadian students were learning in an atmosphere full of freedom and encouragement as the students were respected for their topics of study and choices of presentation. Such a pressure-free environment generated space for creative and innovative student work. Chinese teachers valued this way of teaching and admired such advantages. As a result, they adjusted their projects and allowed students more freedom with the presentation of their work. 


\section{Suggestions for Better Collaboration}

In order to foster collaborative relationships, direct and indirect communication was made through various media formats including emails, phone calls, social app messages, and video conferences. The research teams from both sides and the English teachers from the Chinese sister school helped to bridge the linguistic gaps and facilitate school-to-school communication. The communication method highly relied on the research teams to deliver messages from one side to another. However, such communications were insufficient. Teacher participants all agreed that better collaboration is needed in the future. As Loveland, Miyakawa, and Hirayama (2004) indicate, because international collaboration projects are complicated, comprehensive preparation and design are required. Applying this insight to the project, it is advisable that teachers should have a conference prior to formally conducting the project. These preparatory meetings can be set up at the beginning of each school year, and are essential for teachers as they build initial rapport with their international partners. Teachers can make use of this opportunity to brainstorm ideas as well as openly discuss their thoughts. While such meetings took place in this project, it is suggested that such interactions can be held more frequently.

Since the two schools operate at two far-away geographical locations each with different educational systems and cultures, it is believed that the more mutual understanding that is developed, the better effects the understanding will lead to. A virtual learning community through technology is suggested to bridge the two learning spaces. Students who have similar interests can pair-up and seek further communications within the community. Teachers and students can exchange their ideas effectively and promptly, which means that whenever they have a question, they can discuss and come up with solutions on the technology-based platform. Chia and Pritchard's (2014) research found that virtual learning communities benefit students' interpersonal collaboration and exchanges. It is believed that an online learning community can foster better cultural understanding and collaboration, and from there, the better reciprocity will be achieved.

In this study, students were asked to work either individually or in groups. Student groups were formed with their home-county partners. Video conferencing meetings provided limited space for student sharing. Not all students could showcase their work. Future practice should try to form bi-national student groups. That is, students can work on the same topics in a small group with partners from their sister school. This will leverage the strength of both sides and generate better intercultural communication and collaboration. Again, technology can be used to facilitate the group communication (Yang et al., 2014). This will allow students to communicate their thoughts deeply in a virtual space without distracting other people. Setting up in-depth communications will have various benefits to students, as O’Neill (2007) found, and students' social interaction, writing, and reading skills can be developed.

\section{References}

Beaton, A. E., Martin, M. O., Mullis, I. V., Gonzalez, E. J., Smith, T. A., \& Kelly, D. L. (1996). Science achievement in the middle school years: IEA's Third International Mathematics and Science Study. Chestnut Hill, MA: Boston College. 
Bell, S. (2010). Project-based learning for the 21st century: Skills for the future. The Clearing House, 83(2), 39-43.

Berg, B. L. (2009). Qualitative research methods for the social sciences (7th ed.). Boston, MA: Pearson.

Boud, D. (1999). Situating academic development in professional work: Using peer learning. International Journal for Academic Development, 4(1), 3-10.

Broadfoot, P. (2000). Comparative education for the 21st century: Retrospect and prospect. Comparative Education, 36(3), 357-371.

Burns, R. B. (1994). Introduction to research methods. Melbourne, Australia: Longman Cheshire.

Carney, S. (2009). Negotiating policy in an age of globalization: Exploring educational "policyscapes" in Denmark, Nepal, and China. Comparative Education Review, 53(1), 63-88.

Carnoy, M., Khavenson, T., Loyalka, P., Schmidt, W. H., \& Zakharov, A. (2016). Revisiting the relationship between international assessment outcomes and educational production. American Educational Research Journal, 53(4), 1054-1085.

Chang Rundgren, S. N. (2015). Is the moon more round in the Western world? Some important aspects of comparative education. Cultural Studies of Science Education, 10(3),707-718.

Chia, H. P., \& Pritchard, A. (2014). Using a virtual learning community (VLC) to facilitate a crossnational science research collaboration between secondary school students. Computers \& Education, 79, 1-15.

Connelly, F. M., \& Xu, S. (2015, May). Reciprocal learning: Comparative models and the partnership project. Keynote presented at the 2nd Annual Conference: Reciprocal Learning \& Symbiotic Relationships in School Development, East China normal University, Shanghai, China.

Cowen, R. (2006). Acting comparatively upon the educational world: Puzzles and possibilities. Oxford Review of Education, 32(5), 561-573.

Gillespie, K. L., \& Melber, L. M. (2014). Connecting students around the world through a collaborative museum education program. Journal of Museum Education, 39(1), 108-120.

Hofstein, A., \& Rosenfeld, S. (1996). Bridging the gap between formal and informal science learning. Studies in Science Education, 28, 87-112.

International Association for the Evaluation of Educational Achievement [IEA]. (2018). Studies. Retrieved from http://www.iea.nl/our-studies

Lewis, S., Sellar, S., \& Lingard, B. (2016). PISA for schools: Topological rationality and new spaces of the OECD's global educational governance. Comparative Education Review, 60(1), 27-57.

Ligorio, M. B., \& Van der Meijden, H. (2007). Teacher guidelines for cross-national virtual communities in primary education. Journal of Computer Assisted Learning, 24(1), 11-25.

Loveland, T., Miyakawa, H., \& Hirayama, Y. (2004). International collaboration in secondary level education. Journal of Technology Studies, 30(3), 10-19.

Miles, M. B., Huberman, A. M., \& Saldana, J. (2014). Qualitative data analysis (3rd ed.). Thousand Oaks, CA: Sage.

O'Neill, E. J. (2007). Implementing international virtual elementary classroom activities for public school students in the U.S. and Korea. Electronic Journal of e-Learning, 5(3), 207-218.

Punch, K. F. (2005). Introduction to social research: Quantitative and qualitative approaches (2nd ed.). London, UK: Sage.

Robertson, A. (2007). Development of shared vision: Lessons from a science education community collaborative. Journal of Research in Science Teaching, 44(5), 681-705.

Tan, J. C., \& Chapman, A. (2016). Project-based learning for academically-able students. Rotterdam, ZH: Sense. 
Southwest University Affiliated High School. (2014). Introduction to the school. Retrieved from http://www.xndxfz.com/newsShow.asp?dataID=533

Thomas, J. W. (2000). A review of research on project-based learning. San Rafael, CA: Autodesk Foundation. Retrieved from https://www.bie.org/object/document/a_review_of_research_ on project based learning

Underwood, J., Smith, H., Luckin, R., \& Fitzpatrick, G. (2007). E-Science in the classroom: Towards viability. Computers \& Education, 50(2), 535-546.

Wang, C. M. (2012). Using Facebook for cross-cultural collaboration: The experience of students from Taiwan. Educational Media International, 49 (1), 63-76.

Xu, S. J., \& Connelly, F. M. (2017). Reciprocal learning between Canada and China in teacher education and school education: Partnership studies of practice in cultural context. Frontiers of Education in China, 12(2), 135-150.

Yang, J., Yu, H., Chen, S. J. \& Huang, R. (2014). Strategies for smooth and effective cross-cultural online collaborative learning. Journal of Educational Technology \& Society, 17(3), 208-221.

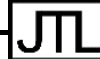

